\title{
A role for actomyosin contractility in Notch signaling
}

\author{
Ginger L. Hunter ${ }^{1,2,3,7^{*}}$ (D) $\mathrm{Li} \mathrm{He}^{4}$, Norbert Perrimon ${ }^{4}$, Guillaume Charras ${ }^{5,6}$, Edward Giniger ${ }^{1 *}$ and Buzz Baum²,3
}

\begin{abstract}
Background: Notch-Delta signaling functions across a wide array of animal systems to break symmetry in a sheet of undifferentiated cells and generate cells with different fates, a process known as lateral inhibition. Unlike many other signaling systems, however, since both the ligand and receptor are transmembrane proteins, the activation of Notch by Delta depends strictly on cell-cell contact. Furthermore, the binding of the ligand to the receptor may not be sufficient to induce signaling, since recent work in cell culture suggests that ligand-induced Notch signaling also requires a mechanical pulling force. This tension exposes a cleavage site in Notch that, when cut, activates signaling. Although it is not known if mechanical tension contributes to signaling in vivo, others have suggested that this is how endocytosis of the receptor-ligand complex contributes to the cleavage and activation of Notch. In a similar way, since Notch-mediated lateral inhibition at a distance in the dorsal thorax of the pupal fly is mediated via actin-rich protrusions, it is possible that cytoskeletal forces generated by networks of filamentous actin and nonmuscle myosin during cycles of protrusion extension and retraction also contribute to Notch signaling.

Results: To test this hypothesis, we carried out a detailed analysis of the role of myosin II-dependent tension in Notch signaling in the developing fly and in cell culture. Using dynamic fluorescence-based reporters of Notch, we found that myosin II is important for signaling in signal sending and receiving cells in both systems - as expected if myosin II-dependent tension across the Notch-Delta complex contributes to Notch activation. While myosin II was found to contribute most to signaling at a distance, it was also required for maximal signaling between adjacent cells that share lateral contacts and for signaling between cells in culture.

Conclusions: Together these results reveal a previously unappreciated role for non-muscle myosin II contractility in Notch signaling, providing further support for the idea that force contributes to the cleavage and activation of Notch in the context of ligand-dependent signaling, and a new paradigm for actomyosin-based mechanosensation.
\end{abstract}

\section{Background}

The actin cytoskeleton plays a major role in the regulation of cell shape and tissue organization in animals [1], and as such is tightly regulated in space and time downstream of many gene regulatory networks and signaling cascades $[2$, 3]. Conversely, recent work has shown that actin-based protrusions and the forces generated in the actomyosin cortex can also influence the ability of cells to send and receive signals from their environment $[4,5]$. This realization spawned the field of mechanotransduction [6]. In considering how mechanical forces might influence cell behavior, it has been proposed that the application of force

\footnotetext{
*Correspondence: ghunter@clarkson.edu; ginigere@ninds.nih.gov ${ }^{1}$ National Institute of Neurological Disorders and Stroke, NIH, Bethesda, MD 20892, USA

Full list of author information is available at the end of the article
}

to a transmembrane protein complex that is coupled to the cytoskeleton leads to a tension-dependent conformational change. This exposes hidden sites in one or more mechanosensitive proteins that are then read in order to initiate a signal [7].

While few signaling systems other than cell-cell and cell-ECM contacts have been shown to be force sensitive, recent work has implicated mechanical force in the activation of Notch receptor [7-12]. In cell culture, pulling forces of between 3.5 and $5.5 \mathrm{pN}$ are required to expose the S2 site of Notch required for cleavage and Notch activation. Importantly, although it is not yet possible to accurately determine levels of tension experienced by Notch-Delta complexes in vivo, this phenomenon is thought to explain the requirement for actin-mediated endocytosis in Notch signaling, whereby

(c) The Author(s). 2019 Open Access This article is distributed under the terms of the Creative Commons Attribution 4.0 International License (http://creativecommons.org/licenses/by/4.0/), which permits unrestricted use, distribution, and 
Delta endocytosis generates sufficient force to induce Notch cleavage and activation [13, 14]. However, it is also clear that the actomyosin cytoskeleton itselfwhether through the activity of protrusions, at the cell cortex, or elsewhere in the cell-generates contractile forces that could influence signaling. In fact, it is hard to understand how endocytosis could generate the force necessary to unfold Notch in the absence of a rigid or contractile actomyosin cortex upon which to pull and/or push against. These considerations raise the question of whether there are instances in which forces generated by the actomyosin cytoskeleton contribute to the activation of Notch [15-17]. As a specific system in which to test this general idea, we used the fly notum [18-20], taking of advantage of the fact that epithelial cells in this tissue engage in local Notch-Delta signaling via lateral cell-cell contacts and signaling at a distance, which is mediated by long actin-rich protrusions. Since Notch signaling influences the decision of cells to assume a bristle or epithelial fate, this process of lateral inhibition leads to the emergence of a pattern of well-spaced bristles.

In the Drosophila pupal notum, the activation of Notch is induced via contact with a neighboring cell expressing Delta. This represses the pro-neural fate so that epithelial cells in which Notch is activated tend to remain epithelial in character $[18,20]$. Conversely, the maintenance of low levels of Notch activation during this window of development allows the expression of pro-neural genes, which drive cells towards a mechanosensory bristle fate. Here, we investigate the role of actomyosin contractility in Notch signaling during this process using a combination of quantitative live cell imaging and genetic manipulations. By genetically and pharmacologically modulating myosin II activity in vivo, we demonstrate the presence of actomyosin-based forces between basal cellular protrusions in an epithelium. At the same time, we show that a robust Notch response requires myosin II-mediated contractility in both signal sending and receiving cells in vivo and in a cell culture model of Notch-Delta signaling. These data show that decreased myosin II activity is associated with defects in Notch-dependent bristle spacing, making clear the importance of actomyosin-based forces in tissue patterning.

\section{Results}

Myosin II activity is required for robust Notch signaling

Myosin II motors contribute to the generation of actindependent pulling forces to drive a wide range of developmental processes [21-23]. In order to determine whether actomyosin contractility is required for lateral inhibition signaling during notum pattern formation, we asked how decreasing actomyosin tension affects the activity of a transcriptional reporter of Notch signaling, $\mathrm{N}^{\text {sfGFP }}$ (Fig. 1a, b) [24]. We measured the average accumulation of GFP over time as a reporter of Notch activity (hereafter, rate of Notch response; see the "Methods" section for more detail). We then used the GAL4/UAS expression system to perturb the function of non-muscle myosin II in this background. Non-muscle myosin II is a multimeric motor protein complex whose heavy chain is encoded by the Drosophila gene zipper, and regulatory light chain (RLC) is encoded by spaghetti squash $[25,26]$. Previous work showed that loss of function mutations and/or expression of dominant negative derivatives of zipper or RLC leads to phenotypes consistent with decreased cortical tension [22, 27]. Since animals homozygous mutant for null alleles of zipper (or spaghetti squash) are not viable to pupariation, we used tissue-specific expression of constructs designed to perturb myosin II function in specific populations of cells to assess the impact of myosin II on Notch signaling in the notum. These include Zipper $^{\mathrm{DN}}$, a motor-less heavy chain protein that binds and sequesters wild-type heavy chain, thus lowering contractility [22], a nonphosphorylatable variant of the RLC, spaghetti squash ${ }^{\mathrm{AA}}$ [27], or RNAi-mediated silencing of Rho kinase (ROK), an upstream activator of myosin II contractility [28]. In our experiments, we find that these constructs are associated with phenotypes of varying severity. The expression of Zipper $^{\mathrm{DN}}$ was associated with the strongest phenotypes, followed by spaghetti squash ${ }^{\mathrm{AA}}$, while the expression of RNAi constructs had the least severe effect. This is consistent with the known ability of these reagents to disrupt myosin activity: RNAi constructs are the weakest, in part due to the long-half-life of targeted proteins (especially Zipper); spaghetti squash ${ }^{\mathrm{AA}}$ blocks activation of myosin and has an intermediate effect, whereas Zipper ${ }^{\mathrm{DN}}$ is a powerful dominant negative that prevents assembly of endogenous myosin II.

In order to reduce myosin II activity, we expressed UAS-spaghetti squash ${ }^{\mathrm{AA}}$ or UAS-ROK RNAi in signal sending cells (SOP cells, using neuralized-GAL4) or in both signal sending and receiving cells (using pannier-GAL4) [29, 30]. Strikingly, reducing myosin II activity in signal sending cells was sufficient to decrease the rate of the Notch response in adjacent, wild-type neighbor cells (Fig. 1c, d; Additional file 1: Figure S1A-B), and in distant neighbors that signal to one another via basal actin-based protrusions (Fig. 1b, e, f; Additional file 1: Figure S1C). Similar effects were observed when myosin II activity was simultaneously compromised in both signal sending and receiving cells (Fig. 1g-i; Additional file 1: Figure S1D-E). In this case, the decrease in Notch response was more profound in distant neighbours. These data suggest that myosin II plays a critical role in Notch-Delta signalling, particularly between cells that contact one another via long, basal protrusions. 


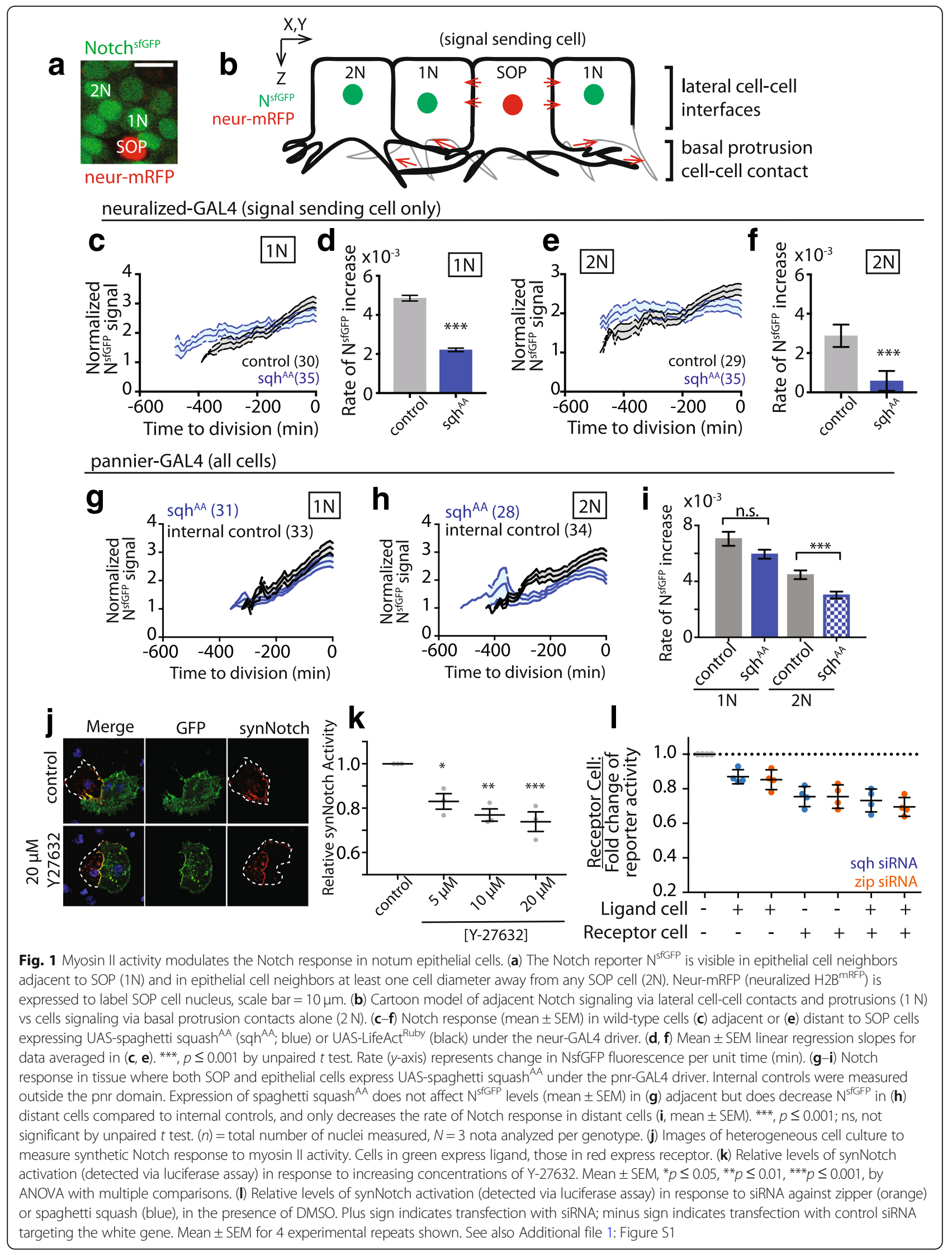


To test whether this represents a general role for myosin II in Notch signaling, we used a cell culture model of lateral inhibition [7]. This consists of a mixed populations of Drosophila S2R + cells expressing either a synthetic Notch ligand or receptor. Once these form cell-cell contacts, myosin II is inhibited by pharmacological inhibitors or dsRNA-mediated knockdown of zipper or spaghetti squash expression (Fig. 1j-l) [31]. A luciferase-based transcriptional reporter is then used to measure Notch activity. Importantly, while acute treatment of the ROK inhibitor Y-27632 altered S2R+ cell shape, it did not change expression levels of ligand or receptor (Fig. 1j; Additional file 1: Figure S1F). Nevertheless, ligandinduced Notch signaling in this system was reduced by Y-27632 treatment in a dose-dependent manner (Fig. 1k; Additional file 1: Figure S1G). The role of cortical actomyosin-based tension in Notch signaling was confirmed using dsRNA-mediated knockdown of zipper or spaghetti squash expression (Fig. 11). Moreover, by mixing control and dsRNA-treated cells, we showed that the maximal Notch response in this system requires myosin II in both signal sending and receiving cells. These findings support a general role for actomyosin contractility in driving a robust Notch response.

\section{Loss of myosin II activity disrupts bristle patterning}

We monitored bristle density in these flies to test whether these tension-dependent changes in the Notch response are sufficient to induce changes in lateral inhibition tissue patterning. Previous research had shown that decreased Notch signaling leads to both the formation of adjacent bristles and to an overall increase in the density of bristles [32]. The effect of non-muscle Myosin perturbations on patterning was much less severe than this. As a quantitative test of the impact of myosin on Notch-Delta-dependent lateral inhibition signaling, we measured the spacing between SOP cells in animals with decreased myosin II activity in signal sending cells (Fig. 2a). The expression of dominant negative

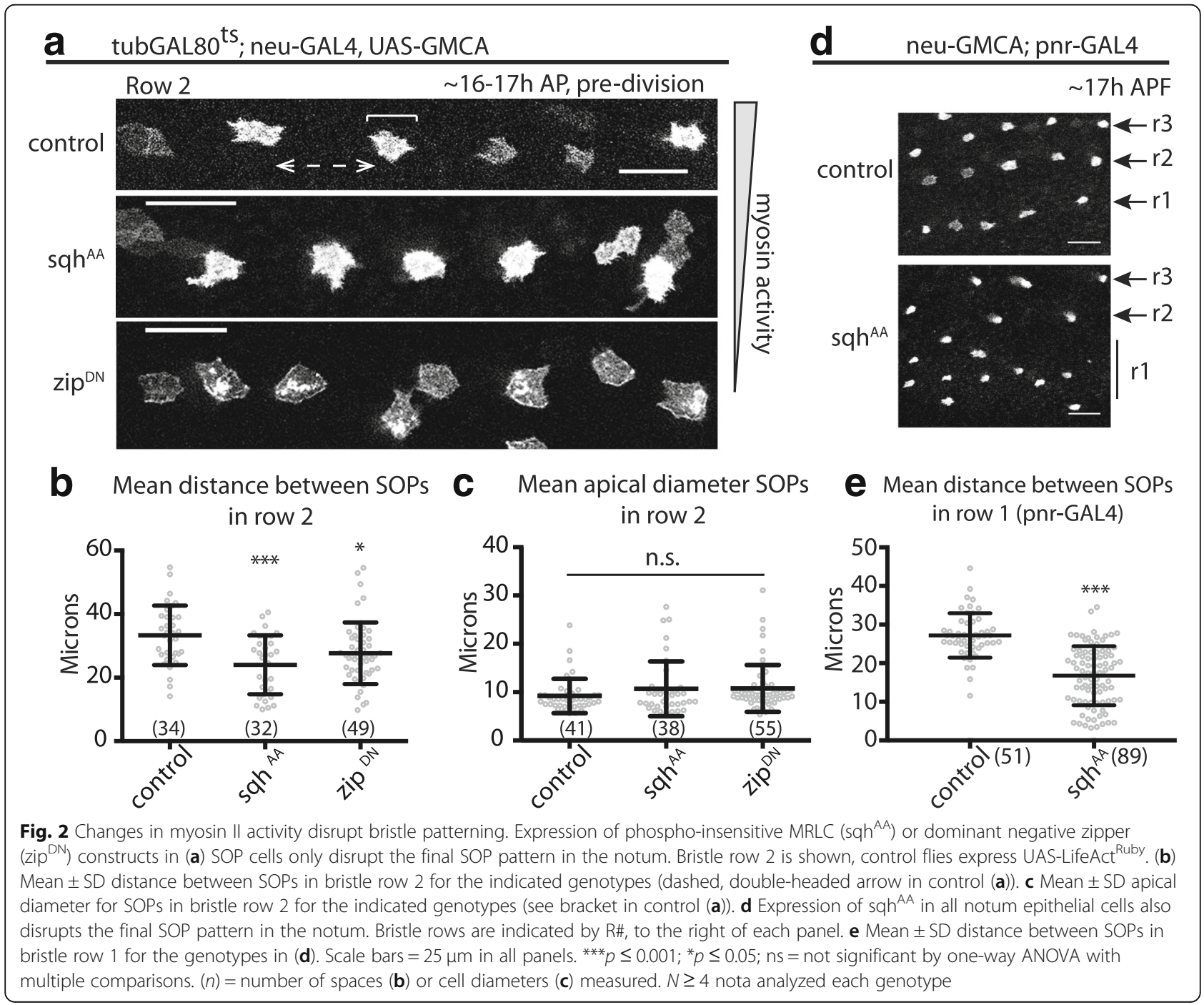


myosin II, a treatment that leads to a strong reduction in myosin II activity, was associated with decreased spacing between SOP cells in rows, without altering SOP cell clustering (Fig. 2a-c). Similar results were seen in flies expressing spaghetti squash ${ }^{A A}$ in signal sending cells, leading to a reduction in pattern spacing (Fig. $2 \mathrm{a}-\mathrm{c}$ ). Furthermore, the expression of spaghetti squash ${ }^{A A}$ throughout the notum led to a decrease in bristle spacing (Fig. 2d, e)-a phenotype that was most evident in bristle row 1-but again, not to the formation of SOP cell clusters. Although we did not observe any disruption of the overall notum epithelium organization prior to cell division in animals expressing spaghetti squash $^{A A}$ under pnr-GAL4, we cannot rule out subtle changes in this case or following the expression of zipper $^{D N}$. Together, these data suggest actomyosin-based tension has a profound impact on long-range, protrusion-mediated Notch signaling without influencing signalling between cells that interact with one another via lateral contacts.

\section{The role of actomyosin contractility in the Notch signaling pathway}

First, to ask how actomyosin contractility contributes to the activity of the Notch signaling pathway, we considered the possibility that non-muscle myosin II activity is required for the Notch receptor and/or Delta ligand to be presented on the surface of signal sending and receiving cells [17]. However, when we visualized Notch receptor and Delta ligands in SOP cells, we did not observe myosin-dependent changes in their localization (Notch - apical and basal puncta; Delta - cytoplasmic or basal puncta) or Delta (cytoplasmic or basal puncta) (Additional file 2: Figure S2). Notch and Delta were also observed along the length of protrusions regardless of myosin II status ( $n>6$ nota each genotype; Fig. 3a-c). Thus lowering myosin II activity does not appear to grossly affect the localization of Notch or Delta.

Next, we asked whether myosin II activity has an impact on basal protrusion morphology or dynamics. This is important, since previous genetic and mathematical modeling data show that reductions in the length or dynamics (i.e., retraction, extension) of basal protrusions can lead to defects in long-range Notch signaling and, therefore, to decreased SOP cell spacing [33, 34]. We used time-lapse confocal microscopy to track the dynamics of basal protrusions in live SOP cells (Additional file 3: Movie S1) marked using cell-type-specific expression of the filamentous actin reporter GMCA, the GFP-tagged actin binding domain of Moesin (Fig. 4) [35]. Basal protrusions exhibited cycles of extension and retraction with a period of $\sim 10 \mathrm{~min}$, with an average maximum length of $10 \mu \mathrm{m}$, consistent with previously published data [33]. Protrusions changed shape prior to and during retraction (Additional file 3: Movie S1) through a process reminiscent of helical buckling observed in mechanically active filopodia in cell culture

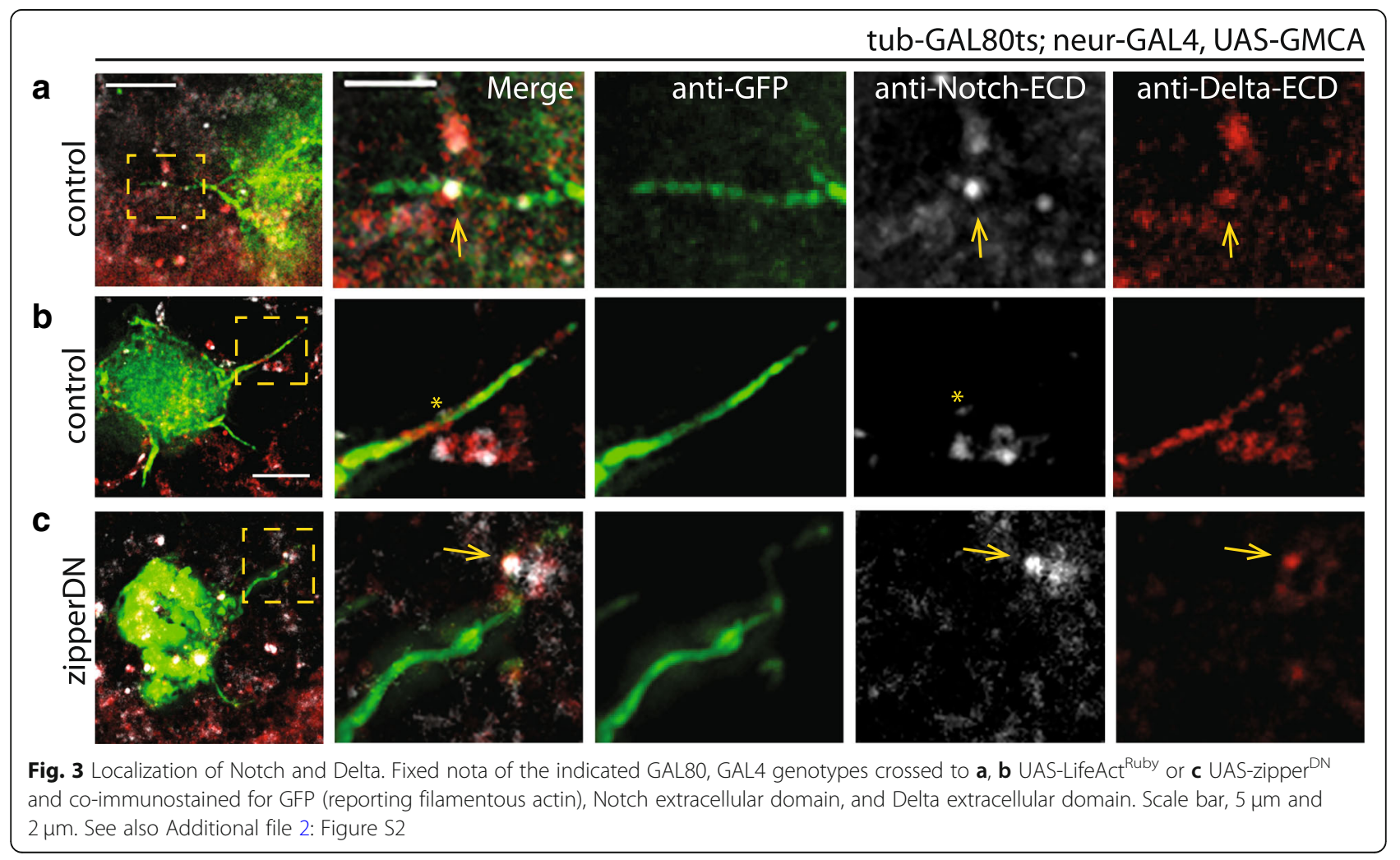




\section{a}

\begin{tabular}{|c|c|c|c|}
\hline mean $\pm S D$ & control & $\operatorname{sqh}^{A A}$ & zipper ${ }^{\mathrm{DN}}$ \\
\hline Total length $(\mu \mathrm{m})$ & $9.1 \pm 3.6$ & $8.3 \pm 2.4$ & $7.4 \pm 2.0 *$ \\
\hline $\begin{array}{l}\text { Extension rate } \\
(\mathrm{nm} / \mathrm{s})\end{array}$ & $27.1 \pm 14.9$ & $23.1 \pm 11.1$ & $24.0 \pm 17.9$ \\
\hline $\begin{array}{l}\text { Retraction rate } \\
(\mathrm{nm} / \mathrm{s})\end{array}$ & $34.2 \pm 22.2$ & $27.5 \pm 16.5$ & $26.7 \pm 15.4$ \\
\hline Lifetime (min) & $9.9 \pm 4.2$ & $10.2 \pm 4.6$ & $10.7 \pm 4.9$ \\
\hline${ }^{*} p \leq 0.05$ & $\begin{array}{c}\mathrm{n}=56 \text { filo; } \\
20 \text { cells; } \\
3 \text { nota }\end{array}$ & $\begin{array}{c}\mathrm{n}=50 \text { filo; } \\
19 \text { cells; } \\
3 \text { nota }\end{array}$ & $\begin{array}{c}\mathrm{n}=48 \text { filo; } \\
19 \text { cells; } \\
3 \text { nota }\end{array}$ \\
\hline
\end{tabular}

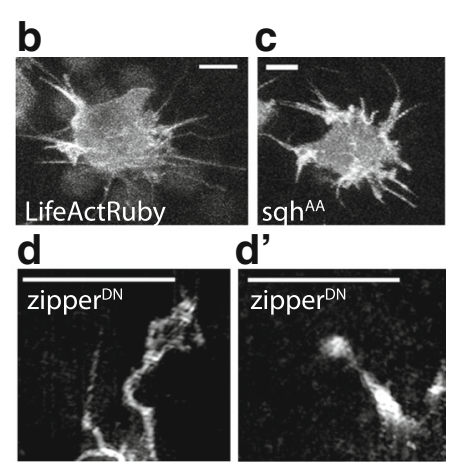

Fig. 4 Effect of decreased myosin II activity on protrusion dynamics and morphology. (a) For the listed genotypes, we measured maximum protrusion length (from cell body to tip), rate of extension (time to maximum length), rate of retraction (time to disappearance into cell body), and protrusion lifetime. (b-d') Live imaging of SOP cells in nota of the indicated genotype show that overexpressing sqh ${ }^{\text {AA }}$ does not appear to affect basal protrusion morphology, but overexpression of zipperDN does lead to abnormal protrusion shapes. Scale bars, $5 \mu \mathrm{m}$. ${ }^{*} p \leq 0.05$, by unpaired $t$ test. See also Additional file 3: Movie S1 and Additional file 4: Movie S2

[36]. Importantly, however, the behavior of protrusions appeared similar in both control and spaghetti squash ${ }^{A A}$ expressing tissues (Additional file 4: Movie S2), and their morphology was unaffected by the expression of spaghetti squash $^{A A}$ (Fig. 4a-c). However, when we induced a strong loss of myosin II activity via expression of the dominant negative construct, we observed changes in the length and morphology of protrusions (e.g., bulbous tips, fanning) (Fig. 4d, d'), similar to those seen following myosin inhibition in cell culture [37]. We conclude that while decreased myosin II activity can lead to protrusion defects, the incidence of these defects does not correlate with the reduction in protrusion-mediated long-range Notch signaling that we observed in animals expressing spaghetti squash $^{A A}$.

\section{Actomyosin contractility and endocytosis influence Notch} signaling in distinct ways

How might the actomyosin cortex influence Notch signaling? Endocytosis requires deformation of the cell cortex, whose stiffness is regulated by actomyosin contractility [38, 39]. At the same time, the forces generated during ligand internalization have been proposed to drive the mechanical activation of Notch receptor [7, 9, 40]. This made it important to test whether the impact of actomyosin contractility on signaling and on lateral-inhibition patterning in vivo functions through its effects on endocytosis.

To do so, we first examined the ability of cells with reduced myosin II activity to endocytose Delta ligand using a ligand uptake assay [41]. Delta-positive puncta were observed in both control and zipper ${ }^{D N}$ expressing cells without these being a visible difference in the numbers of these puncta (Additional file 5: Figure S3A).

We next used dsRNA to silence known regulators of Delta endocytosis and myosin II activity to determine how the two effects combine to influence long-range Notch signaling. Decreased Delta endocytosis in SOP cells, induced by RNAi-mediated silencing of the epsin liquid facets (lqf) [42], led to a slight increase in the numbers of SOP cell clusters $(10.7 \pm 3.8$ SOP pairs per LqfRNAi nota vs $4.5 \pm 1.8$ SOP pairs per control nota, $N \geq 3$ nota each genotype; Additional file 5: Figure S3B-E), which is consistent with the requirement for epsins in Notch-Delta signalling (Note this phenotype differs from that seen following reductions in myosin II activity) $[40,42]$. We then combined these perturbations While the animals expressing dsRNAs that target each system alone had weak bristle patterning defects (Fig. $5 \mathrm{a}$ ), when we co-expressed zipper- and lqf-RNAi in SOP cells (using tubulin-GAL80 ${ }^{\text {ts }}$ to temporally control RNAi expression so that the animals remained viable), we observed severe patterning defects. These appeared to be a combination of the two phenotypes observed in the single mutants, i.e., there was an increase in the variability of bristle spacing together with an enhanced number of GFP-positive cell clusters relative to the expression of either RNAi alone (Fig. 5a, b; Additional file 5: Figure S3F). These data support the idea that Delta ligand endocytosis and myosin II activity act in distinct ways to impact Notch signaling in vivo via lateral and protrusion-mediated signaling, respectively.

This result was further supported by experiments performed in cell culture using the synthetic Notch system, where we perturbed both myosin II activity and endocytosis via dsRNA and pharmacological inhibition (Fig. 5c-d; Additional file 1: Figure $\mathrm{S} 1 \mathrm{H}$ ). As previously published, Dynasore, an inhibitor of dynamin-mediated endocytosis [43], decreases Notch activation in this system [7]. Strikingly, when Dynasore was used in combination with Y-27632, we observed a further reduction in Notch response (Fig. 5c). Moreover, additive effects were 


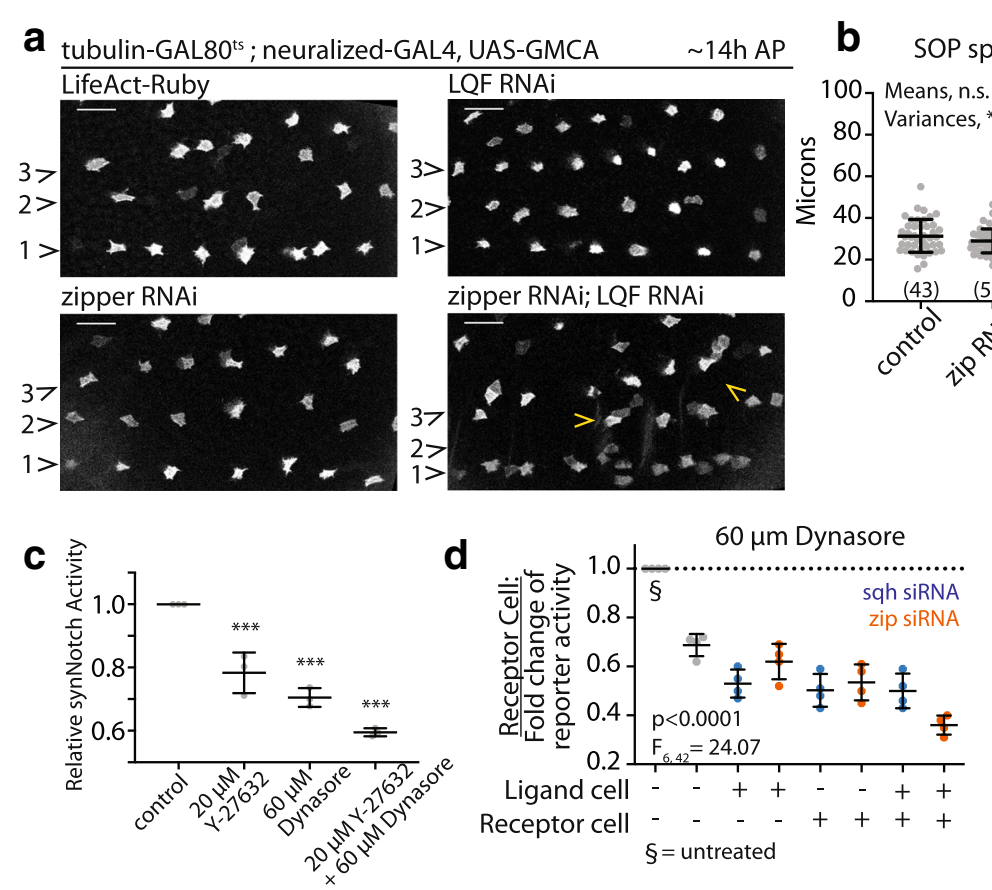

Fig. 5 Overlapping roles of endocytosis and myosin II activity for Notch activation. a SOP cell patterns for pupae of the indicated genotypes. Bristle rows 1-3 shown (indicated to the left of each panel). Scale bars, $25 \mu \mathrm{m}$. b Mean \pm SD distance between SOP cells along bristle row 3 at $14 \mathrm{~h}$ AP for genotypes in (a); $(n)=$ pairs measured, $N \geq 3$ pupae per genotype. n.s. by one-way ANOVA. ${ }^{* * *} p<0.0001$ by Brown-Forsythe test, $F_{3,2} 225=9.71$. (c) synNotch activation in S2R+ heterogeneous populations treated with $y$-27632 alone, dynasore alone, or $y-27632$ and dynasore together. Mean \pm SEM shown, ${ }^{* * *} p \leq 0.001$ by ANOVA with multiple comparisons. $\mathbf{d}$ Relative levels of synNotch activation in response to siRNA against zipper (orange) or spaghetti squash (blue) in the presence of $60 \mu \mathrm{M}$ dynasore. Plus sign indicates transfection with siRNA, Minus sign indicates transfection with control siRNA targeting the white gene. Mean \pm SEM for 4 experimental repeats shown. $p$ values determined by two-way ANOVA. Interaction term is not significant $\left(F_{6,42}=1.62\right)$. See also Additional file 5: Figure $\mathrm{S3}$

observed in experiments in which we used dsRNAs to target either zipper or spaghetti squash expression in signal sending or receiving cells in the presence or absence of Dynasore (Fig. 5d). Again, these data point to myosin II activity and endocytosis having distinct functions in the regulation of Notch signaling.

\section{Interacting protrusions are under mechanical tension}

While the apical actomyosin cytoskeleton is known to control many aspects of notum cell biology [21, 30, 44], little is known about its impact on basal protrusions. If myosin II were to contribute to Notch signaling by enabling protrusions that make adhesive contacts to exert forces on one another, several preconditions would have to be met. Myosin II would have to be (i) present and active within the basal domain of cells and (ii) generate pulling forces between these protrusions. When we imaged myosin II in the basal-most focal plane of the tissue using the Venus-tagged myosin II heavy chain gene trap [45], myosin II was visible along the length of protrusions and at their base, where it co-localized with filamentous actin (Fig. 6a-a"). In order to determine whether this basal myosin II pool is likely to generate forces we imaged phosphorylated endogenous RLC
(pMRLC, phospho-myosin regulatory light chain [27]). We observed pMRLC (and thus active myosin II) localized in clumps at the base of protrusions in SOP cells (Fig. 6b-b"; Additional file 6: Figure S4A). These data are consistent with models in which the contractile actomyosin meshwork at the base of cellular protrusions contributes to retrograde flow, amplifying actin treadmilling within the protrusion $[46,47]$.

Having established the presence of myosin II in and at the base of protrusions, we wanted to assess the extent of contacts between the basal domain of cells in the notum. These can be visualized using the GRASP system (GFP reconstitution across synaptic partners) [48]. Membrane-bound GFP $^{1-10}$ was expressed in signal receiving cells (via pnr-GAL4) and $\mathrm{GFP}^{11}$ in signal sending cells (via ase-LexA, with LexAOp-GAL80 to inhibit GAL4 activity), so that the reconstituted GFP fluorescence would be visible only when the two cell types came into contact with one another (Fig. 6c; Additional file 6: Figure $\mathrm{S} 4 \mathrm{~B})$. In control tissues expressing $\mathrm{GFP}^{1-10}$, we observed background levels of fluorescence (Fig.6 c'). In control tissues where all cells express both $\mathrm{GFP}^{1-10}$ and $\mathrm{GFP}^{11}$, we observe that all cell membranes fluoresce, including the nuclear envelope (Fig. 6c"). However, when 


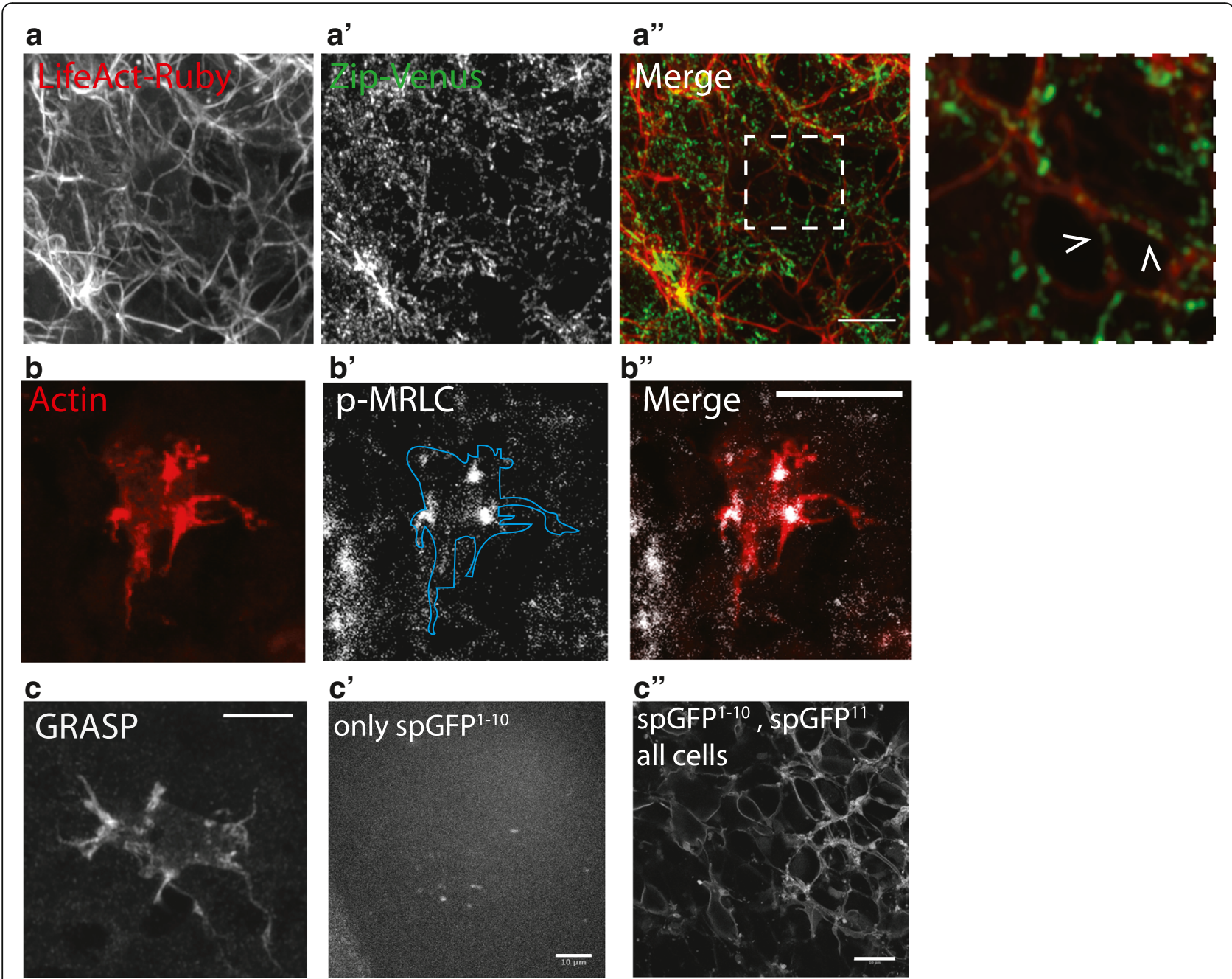

Fig. 6 Protrusion contacts and Myosin II localization. (a-a") Filamentous actin in the basal protrusions co-localizes with myosin II heavy chain (visualized with Venus) in notum explant. Images are a z-projection $\sim 2 \mu \mathrm{m}$ basal to the cytoplasm of notum epithelium, where basal protrusions dominate. (b-b") Phosphorylated MRLC (p-MRLC, spaghetti squash) localizes to the cell-proximal base of basal protrusions in fixed nota. (c-c") Image from a fixed nota of the indicated genotype, GRASP (reconstituted membrane bound GFP) indicates the extent of cell-cell contacts between signal sending (pictured) and receiving cells. (c) A single SOP cell expressing GFP ${ }^{11}$ with neighboring epithelial cells expressing GFP ${ }^{1-10}$. (c') A single SOP cell expressing GFP ${ }^{11}$ with neighboring epithelial cells not expressing any GFP ${ }^{1-10}$. (c') Expression of both GFP fragments in all notum cell types. Scale bars: for $\mathbf{b}^{\prime \prime}, \mathbf{c}=5 \mu \mathrm{m}$; for $\mathbf{a}^{\prime \prime}, \mathbf{c}^{\prime} \mathbf{c}^{\prime \prime}=10 \mu \mathrm{m}$. See also Additional file 6: Figure $\mathrm{S} 4$

we assessed the ability of single GFP11 cells to contact their neighbours, we saw that basal cell-cell contacts are not restricted to protrusion tips, but are extensive and run along the length of the protrusions (Fig. 6c). These data indicate that protrusions form a network of basal cell-cell contacts that effectively extend the range of physical contact between cells in the notum to $2-3$ cell diameters, as suggested previously [33].

In line with this, when we imaged the full set of protrusions in vivo using pannier-GAL4 to express UAS-LifeAct ${ }^{\text {Ruby }}$ in both signal sending and receiving cells in the notum, we observed a complex network of protrusions that criss-crossed the basal surface of the epithelium (Fig. 7a). These networks fluctuate in density over time (Additional file 7: Movie S3). During the window of observation, particle image velocimetry (PIV) [49] revealed that the basal domain is in constant flux (Fig. 7a, b), without there being evidence for tissue-wide polarity. Importantly, this movement was dependent on actomyosin contractility, since it was markedly reduced by treatment with Y-27632 [29]. Acute treatment with Y-27632 led to a steady decrease in the pulsatile movement of basal cell-cell contacts over a period of a few minutes (Fig. 7c, d). These data suggest that basal contacts transmit forces between cells which depend on myosin II.

Finally, to test whether these basal protrusion contacts are subject to mechanical tension tension, we performed laser ablation to disrupt them. Using a focused UV-laser, 


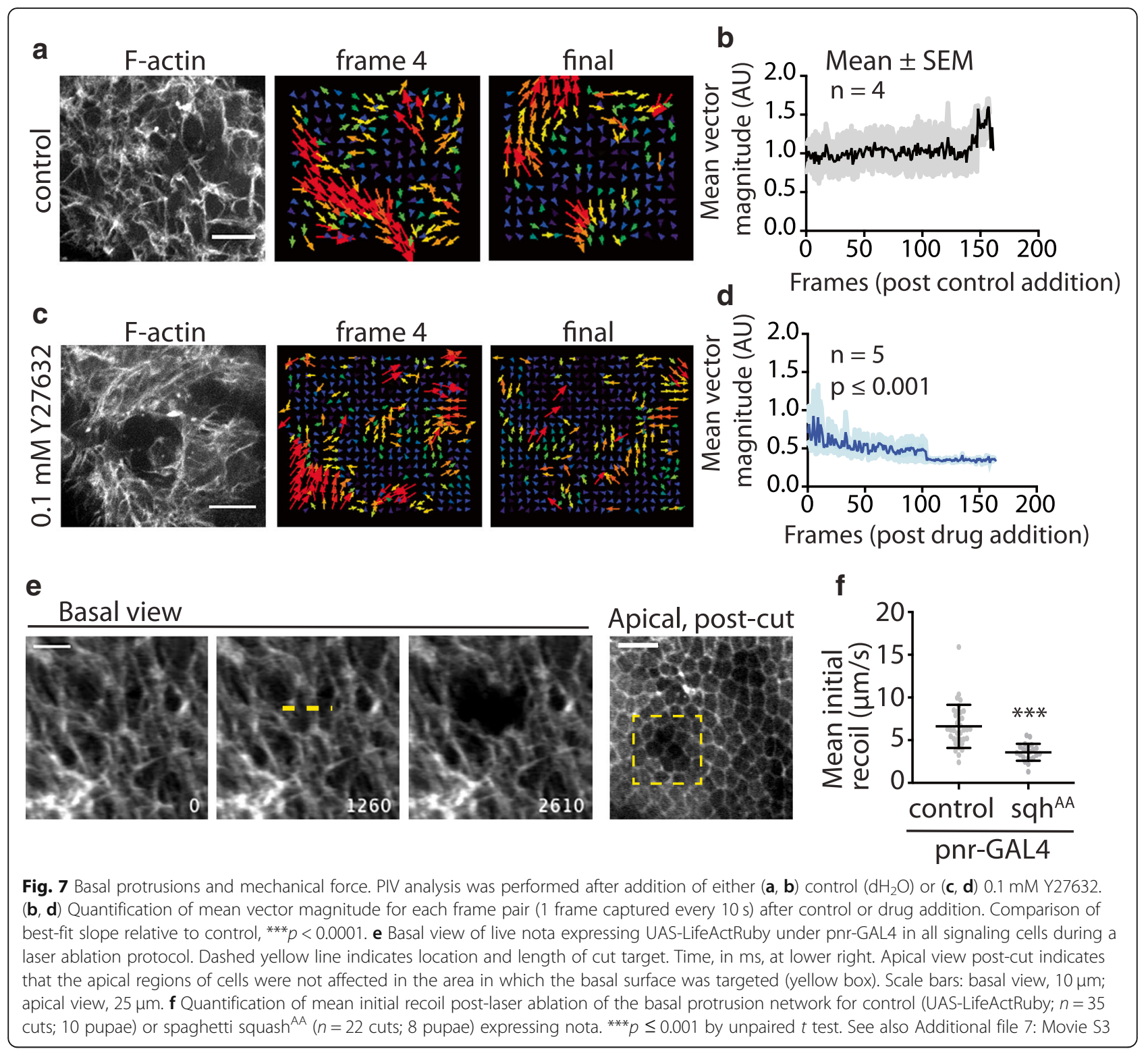

we made $\sim 10-\mu \mathrm{m}$ cuts within the basal surface of the notum, disrupting the protrusion network without affecting more apical planes (Fig. 7e). Cuts induced a rapid recoil, followed by a slower relaxation, as expected for tissues under tension. When we expressed the spaghetti squash $^{A A}$ construct under the pnr-GAL4 driver to reduce myosin II activity throughout the notum, we observed a twofold decrease in the mean initial recoil velocity, from $6.6 \pm 2.5 \mu \mathrm{m} / \mathrm{s}$ (mean $\pm \mathrm{SD}, n=35$ cuts, 10 pupae; Fig. $7 \mathrm{f})$ to $3.6 \pm 1.0 \mu \mathrm{m} / \mathrm{s} \quad(n=22$ cuts, 8 pupae; $p<0.0001$, unpaired $t$ test). Taken together, these data support a model in which myosin II-dependent tension in basal contacts that connect epithelial cells in the notum facilitate robust activation of Notch response during pattern formation in the notum.

\section{Discussion}

In Drosophila, the pattern of bristles on the dorsal thorax of the fly is set up by Notch-Delta signaling through a process of lateral inhibition [50]. As we show here, this signalling is facilitated by both actomyosin contractility and Epsin-mediated endocytosis [14]. While a reduction in myosin II activity in signal sending cells is not sufficient to induce adjacent cells to adopt the SOP cell fate, in combination with reductions in Epsin function, we observe frequent SOP cell clusters. This suggests that Notch signaling in adjacent neighbors depends on both myosin II-mediated contraction and Epsin-mediated endocytosis forces. The two systems could well work in tandem, since cortical actomyosin may function as a platform that the endocytic machinery can use to exert forces. However, over longer distances, where 
lateral inhibition signaling relies on protrusions, myosin II acts alone. Here, reductions in myosin II activity are sufficient to lead to aberrant cell fate decision making and decreased spacing between SOP cells. For this model of Notch activation to work [33, 34, 51, 52] would require that (i) Notch and Delta localize to protrusions; (ii) that protrusions have physical interactions; (iii) that these protrusion interactions are subject to tension, in order to activate Notch receptor. Here we show that each of these conditions is met.

How might Notch receptor be activated on protrusions? Our data suggests that one way this could occur is through the contact, engagement, and retraction of basal protrusions in Notch and Delta expressing cells. Importantly, since the contact area between protrusions can be extensive, Notch/Delta signaling molecules localized along the protrusions could potentially contribute to signal activation. In addition, when contact has been made, the ligand and receptor could diffuse along the length of the protrusion and become trapped at the site of contact-as suggested previously [53]. Once Notch and Delta have become engaged, actomyosin-dependent extension/retraction cycles could provide shear forces parallel to the plasma membrane that contribute to the activation of Notch. Alternatively, Notch could be activated by the simple pulling of protrusions on one another. Filopodia are able to exert pulling forces on their environment up to $\sim 1 \mathrm{nN}[36,54]$, which is more than sufficient to activate Notch receptor and much higher than the forces associated with endocytosis $[40,55]$. One caveat of our work is that, although we did not observe any change in basal Notch or Delta localization in cells with lowered levels of actomyosin contractility, due to the relatively low levels of basally localized Notch and Delta, we cannot rule out an effect. Development of next generation Notch activity reporters that allow the rapid visualization of local receptor activation in vivo will be necessary to reveal the mechanical details of Notch signaling in cellular protrusions.

While our data do not rule out the possibility that endocytosis contributes directly to protrusion-mediated Notch activation. However, the structure of filopodial-like protrusions, with bundled actin closely associated with the plasma membrane, may be refractory to endocytosis. Indeed there is evidence for the existence of endosomal 'hot spots' at the base of cellular protrusions rather than along them [56]. A closer analysis of the ultrastructure of basal protrusions could help to reveal the impact of local structure on the numbers of endocytic pits formed.

How much does protrusion-mediated Notch-Delta signaling contribute to the cell fate decision making process of epithelial cells? Previously, it was shown that stochastic noise can be a feature of signaling mechanisms and contribute to the plasticity of bristle patterning [57]. More generally, stochastic amplification of noisy signals, especially as part of signaling feedback loops, can drive bistable systems in both models and biological systems [58-61]. This means that the amount of signaling protein present on basal protrusions is likely sufficient to induce changes in cell fate: when two cells beginning to downregulate Notch response and upregulate pro-neural genes are "too close," i.e., within range of each other's basal protrusions, we commonly observe switching away from the SOP fate in at least one of them. Thus, the long-range Delta signal, amplified through the feedback mechanisms which exist to reinforce Notch-mediated cell fate decisions $[62,63]$, is likely sufficient to impose the epithelial fate, even if these proteins are found concentrated at lateral cell-cell contacts [33, 64].

Recent evidence shows that the patterning of bristle rows begins developing in the notum far earlier than $12 \mathrm{~h}$ APF, where we begin our analysis [65]. Although we have observed basal protrusions in fixed nota as early as $9 \mathrm{~h}$ APF (unpublished data), technical challenges prevent us from being able to perform our live analysis of Notch dynamics prior to $12 \mathrm{~h} \mathrm{APF}$. Corson et al. also suggests that bristle patterning terminates prior to $12 \mathrm{~h} \mathrm{APF}$; however, our data clearly show that completion of lateral inhibition-dependent decision making is, at least in some cells, a temporally extended process [66] and these fate choices remain plastic as late as $12 \mathrm{~h}$ APF in wild-type animals. Given that myosin II is able to alter Notch-Delta signaling in cell culture and in vivo, and given the prevalence of protrusions in biological systems [67], it will be important in the future to determine whether actomyosin-dependent protrusion-mediated Notch signaling plays much more general roles in tissue development and homeostasis than currently appreciated.

\section{Conclusion}

Our results show that actomyosin contractility plays a role in Notch signaling both in a cell culture model of signaling and in bristle patterning in the developing fly. By tuning the activity of myosin II to affect contractility without affecting protrusion dynamics and morphology, we show that protrusion interactions are subject to contractile forces and that myosin II activity is required for robust signaling between cells whose only contact is via basal protrusions. Our data also show that, actomyosin contractility in cells that contact one another through extensive lateral contacts promotes the Notch. In these cells endocytosis and myosin-dependent pulling may both contribute to force-dependent Notch activation. These results add to our understanding of protrusion-mediated signaling in the patterning of self-organized tissues. Importantly, they also suggest a new mechanism of mechanotransduction via which 
forces generated within the actomyosin cytoskeleton impact signaling to help pattern a tissue.

\section{Methods}

Fly strains

GAL4 Drivers: tub-GAL80 ${ }^{\text {ts }}$; neu-GAL4, UGM. Neu-

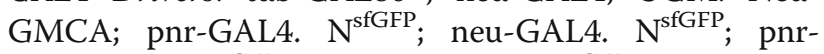

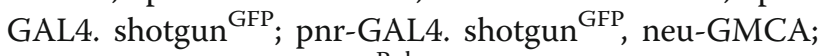
neu-GAL4. UAS-lifeAct ${ }^{\text {Ruby }}$; pnr-GAL4. UAS Responders: UAS-zipper ${ }^{\mathrm{dn}, \text { gfp }}$. UAS-squash ${ }^{\mathrm{AA}}$. UAS-LifeAc$\mathrm{t}^{\text {Ruby }}$. UAS-liquid facets RNAi. UAS-ROK RNAi. UAS-white RNAi UAS-zipper RNAi. Other: zipper ${ }^{\text {Venus, Flag . }}$ GRASP: ase-LexA-p65/CyO(Kr:GFP); LexAOp-GAL80, UAS-CD4spGFP(1-10)/TM6BTb. LexAOp-CD4spGFP(11) /CyO; pnr-GAL4/TM6BTb.

\section{Microscopy}

White pre-pupae were picked and aged to $\sim 12-24 \mathrm{~h}$ AP at $18{ }^{\circ} \mathrm{C}$. Live pupae were removed from pupal case and mounted on a slide as previously described [68]. Final patterns, live imaging of $\mathrm{N}^{\mathrm{sGGFP}}$, ex vivo experiments, and filopodia imaging were performed on either a Leica SPE confocal, $\times 40$ oil immersion objective $(1.15 \mathrm{NA})$ at room temperature or a Nikon EclipseTi, $\times 20(0.75 \mathrm{NA})$ or $\times 60(1.4 \mathrm{NA})$. Localization of myosin in live pupae was performed on a Zeiss LSM880 with AiryScan, $\times 63$ (1.4 NA) oil immersion objective. Fixed nota were imaged on a Leica SPE confocal, $\times 63$ (1.3 NA) oil immersion objective. Fixed SIM images were obtained on a Zeiss Elyra PS.1, × 63 (1.4NA) oil immersion.

\section{Laser ablation}

Live images were acquired on a Zeiss Axio Imager.M2 $\mathrm{m}, \times 40(1.2 \mathrm{NA})$ water objective, using Micromanager (Vale Lab) acquisition software. An Nd:YAG UV laser (Continuum) was interfaced with the confocal microscope to allow steered laser incisions [69]. We made $10-\mu \mathrm{m}$ incisions orthogonal to the anterior-posterior axis at a laser power $\sim 3.0 \mu \mathrm{J}$.

\section{Immunofluorescence}

Primaries: chicken anti-GFP (1:1000, Abcam ab13970, RRID:AB_300798); rabbit anti-pS19-MRLC (1:50, CST 3671); mouse anti-Delta extracellular domain (1:100, DSHB c594.9b, RRID:AB_528194); mouse anti-Notch extracellular domain (1:200, DSHB c458.2H, RRID:AB_528408); guinea pig anti-Delta ECD (1:2000, M. Muskavitch). Secondaries: Rhodamine Red-X anti-guinea pig (1:2000, Jackson ImmunoResearch Labs \#106-295-003, RRID:AB_2337428) and Cy5 anti-mouse (1:2000, Jackson ImmunoResearch Labs \#115-175-146, RRID:AB_2338713); AlexaFluor 488 anti-chicken (1:1000, ThermoFisher Scientific A-11039, RRID:AB_2534096) and AlexaFluor 568 anti-rabbit (1:1000,
ThermoFisher Scientific A-11011, RRID:AB_143157); Texas Red-X Phalloidin (1:500, ThermoFisher Scientific T-7471) were used to visualize F-actin. Nota were mounted in $50 \%$ glycerol or Vectashield (with DAPI, Vector Laboratories) for labeling nuclei.

\section{Ex vivo}

Live nota were dissected and attached to $35-\mathrm{mm}^{2}$ glass bottom dishes (Matek) using a thrombin/fibrinogen (Sigma) clot, then cultured in $250-\mu \mathrm{L}$ modified Clone8 medium (Schneider's insect medium (Sigma), 2.5\% fly extract, 2\% fetal bovine serum (ThermoFisher Scientific) as previously described [68]. After initiation of imaging,

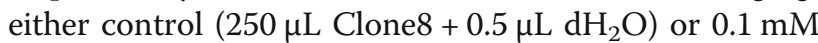
Y27632 $(250 \mu \mathrm{L}$ Clone8 + 0.5 $\mu \mathrm{L} 100$ mM Y27632; Sigma $)$ was added to the dish.

\section{Molecular cloning}

Long hair-pin dsRNA was designed using SnapDragon (DRSC/TRiP Functional Genomics Resources, https://www.flyrnai.org/cgi-bin/RNAi_find_primers.pl). Gene-specific amplicons of sqh, zipper, and white genes were amplified from fly genome by PCR, inserted into pDONR221 vector, and subcloned into pWALIUM10 RNAi vector. All constructs verified by sequencing. The primers used for the synthesis of dsRNA were as follows (F, forward; $R$, reverse), sequence $5^{\prime}-3^{\prime}$ :

\section{sqh F: GGGGACAAGTTTGTACAAAAAAGCAGGCT TCCGGCTCCATTTAGCTCCATTA sqh R: GGGGACCACTTTGTACAAGAAAGC TGGGTGGCAGGACGCCCATATTCTC zipper F: GGGGACAAGTTTGTACAAAAAAGC AGGCTTCCACAGGGTACAGCCGATAAA; zipper R: GGGGACCACTTTGTACAAGAAAGC TGGGTGCTTGTGCTTGCAGCTTCTTC; $w$ F: GGGGACAAGTTTGTACAAAAAAGCAGGCT TCTGCCCAGTGTCCTACCA; $w$ R: GGGGACCACTTTGTACAAGAAAGCTGGGT GTACGAGGAGTGGTTCCTTGA.}

Primers used for qPCR:
GAPDH F: CCAATGTCTCCGTTGTGGA
GAPDH R: TCGGTGTAGCCCAGGATT
sqh F1: CGAGGAGAATATGGGCGTCC
sqh R1: CCTCCCGATACATCTCGTCCA
zipper F: CCAAGACGGTCAAAAACGAT zipper R: GATGTTGGCTCCCGAGATAA

\section{Cell culture}

Drosophila S2R+ cells were grown in Schneider's Drosophila media (Gibco) supplemented with $10 \%$ fetal bovine serum and $0.5 \%$ Pen/Strep (Gibco). Cells were 
transfected using Effectene transfection reagent (Qiagen) [70], with DNA mixture containing: $0.1 \mu \mathrm{g}$ pAct-Gal4, $0.4 \mu \mathrm{g}$ pUAST-dsRNA, $0.01 \mu \mathrm{g}$ pUbi::GBN-Notch-QF, $0.09 \mu \mathrm{g}$ pQUAST-luciferase (for signal receiving cells); $0.1 \mu \mathrm{g}$ pAct-Gal4, $0.4 \mu \mathrm{g}$ pUAST-dsRNA, $0.1 \mu \mathrm{g}$ pUbi::GFP-mcd8-Ser (for signal sending cells). Transfected cells were cultured for 10 days to allow efficient knock-down of target genes. Signal sending and receiving cells were washed twice with fresh culture medium, suspended, and mixed together in 1:1 ratio. Cells were cultured for an additional day before screening luciferase activity (Steady-Glo Luciferase Assay Kit, Promega) using a SpectraMax Paradigm Multi-Mode Microplate Reader. For Dynasore treatment, transfected cells were washed twice by culture medium, incubated with medium containing $60 \mu \mathrm{M}$ Dynasore and/or $20 \mu \mathrm{M}$ Y-27632 (final concentration) for $1 \mathrm{~h}$. Cells were resuspended, mixed in 1:1 ratio, and cultured for an additional day in the presence of Dynasore before luciferase assay. Knock-down efficiency was tested by qPCR. Real-time PCR was performed using iTaq SYBR Green Supermix (Bio-Rad) with GAPDH as a control.

qPCR: S2R+ cells plated in six-well plate were transfected with indicated dsRNAi plasmid $(0.6 \mu \mathrm{g})$ together with pAct-GAl4 $(0.2 \mu \mathrm{g})$ using Effectene. dsRNA against white used as control. The transfection procedure was repeated two more times every 4 days to maximize transfection efficiency. Total RNA was extracted from $\mathrm{S} 2 \mathrm{R}+$ cells after the 3rd transfection using TRIzol Reagent (ThermoFisher Scientific). Raw RNA was treated with DNase I, purified by QIAGEN RNeasy kit, and converted to cDNA template using iScript cDNA Synthesis Kit (Bio-Rad). Y27632 treatment: Cells expressing either synNotch or GFP-ligand were treated with $20 \mu \mathrm{M}$ Y-27632 for $1 \mathrm{~h}$ and then mixed and cultured in the presence of $20 \mu \mathrm{M}$ Y-27632 for 1 day before analysis.

\section{Quantitative analysis and statistics}

All statistical analysis was performed in Prism 6 (GraphPad). Specific tests used are indicated in the text and figure legends, see Additional file 8 for raw data.

Figure 1: $\mathrm{N}^{\mathrm{sfGFP}}$ signal was measured as previously described [24]. Briefly, the $\mathrm{N}^{\text {sfGFP }}$ transgene includes a nuclear localization signal. GFP fluorescence localized to nuclei either adjacent to $(1 \mathrm{~N})$ or one cell removed $(2 \mathrm{~N})$ from an SOP (which lack GFP expression) was measured by drawing an ROI in the nucleus and recording mean intensity for the ROI for each time point until nuclear envelope breakdown (NEB). Since epithelial cells are staggered in their cell fate decision making process, and we previously established that exit from G2 phase of the cell cycle is Notch signaling dependent, we use NEB as a fixed time point for comparison. For the purposes of these graphs, $t=0$ at NEB. The data was normalized to the fluorescence at the first time point of the movie (i.e., time point closest to $12 \mathrm{~h} \mathrm{APF).}$

Figures 2 and 5: Mean distance and apical diameter between SOPs was measured in bristle row 2: an unprojected, z-slice image is rotated to align bristle row 2 with $0^{\circ}$ axis, an ROI is drawn to encompass all SOPs in row 2, and the ROI is collapsed along the $y$-axis to result in a 1D histogram along the bristle row ( $x$-axis). Distance between SOPs is defined as the centroid to centroid distance between signal peaks along the histogram; apical diameter is defined as the edge-to-edge measurement of a signal peak (i.e., where signal reaches 0 ). To verify that we were only measuring the distance between true SOP cells, we captured $12 \mathrm{~h}$ time-lapse movies (starting at $12 \mathrm{~h} \mathrm{APF).} \mathrm{We}$ therefore measured the distance between GFP+ cells which become SOPs and not GFP+ cells that switch back to epithelial fates. However, in measuring grouping, we measured any GFP+ cells adjacent to each other.

Figure 4: Live images were maximum projected. Total length = maximum length from cell-proximal base to tip; extension rate $=$ time for a protrusion to appear until it reaches maximum length; retraction rate $=$ time for a protrusion to disappear after reaching maximum length; lifetime $=$ total time during which a protrusion is visible.

Figure 7: Particle image velocimetry (PIV) was performed using the FIJI plugin described in [49]. Mean vector magnitude (second iteration) for the field of view for each time point pair was calculated. The region shown in the micrograph is the full extent of the analyzed area. We chose ROI of consistent area to measure movement. We picked areas of the excised nota that were relatively flat and close to the coverslip-due to the nature of the experiment excised nota sometimes curl up or fold, and we wanted to measure movement in contiguous regions of tissue. Mean initial recoil is measured by the average movement/time of $\geq 2$ fiducials before and after laser ablation and was performed using the manual spot tracker in Icy [71].

Supplement: Filopodia dynamics were measured by manually tracing protrusions in z-projected time-lapse images. Myosin localization: basal images (up to $1 \mu \mathrm{m}$ maximum projection). ROIs were drawn to include only basal filopodia areas. All other measurements were performed as described in main text figures.

\section{Additional files}

Additional file 1: Figure S1. Contribution of Myosin II activity to Notch response. (A) RNAi against an activator of Myosin II activity, Rho kinase (ROK) in signal sending cells alone does not disrupt protrusion morphology. (B-C) Decreased ROK activity in signal sending cells alone (via neur-GAL4) leads to decreased Notch response in both (B) adjacent and $(C)$ distant wildtype neighboring cells (non-linear regression, comparison of fit, Prism). (D) Decreased ROK activity in all cells (via pnrGAL4) does not affect the rate of signaling between adjacent cells, but 
does decrease the total signal ( $1 \mathrm{~N}$ control vs RNAi elevations, $p<0.001$ by linear regression). (E) The rate of Notch response in distant neighbors is significantly affected by ROK RNAi expression (linear regression, Prism). (F) S2R+ cells expressing synNotch in the absence of ligand expressing cells and cultured in the presence of Y27632 and/or Dynasore do not exhibit changes in their expression of synNotch in response to drug treatment. (G) Acute inhibition of ROK does not significantly alter the basal synNotch activity measured in S2R+ cells expressing synNotch in the absence of ligand expressing cells. (H) Basal synNotch activity is affected by transfection of zip and spaghetti squash siRNA, but not by acute treatment with Dynasore. However, because fold changes of synNotch activity in the presence of GFP-ligand is calculated based on each treatment respectively, the relative fold changes should still primarily reflect the efficiency of synNotch cleavage under different conditions. (PDF $1657 \mathrm{~kb}$ )

Additional file 2: Figure S2. Localization of Notch and Delta with decreased Myosin II activity. In tissues expressing control (LifeActRuby) or sqh $^{\text {AA }}$ constructs in SOP cells (tubGAL80 ${ }^{\text {ts. }}$; neur-GAL4, UAS-GMCA) we observe no differences in (A) Notch localization or (B) Delta localization at a single apical section and basal projection (over $2 \mu \mathrm{m}$ ). Scale bars, $10 \mu \mathrm{m}$ and $5 \mu \mathrm{m}$ (sqh ${ }^{\mathrm{AA}}$ anti-Delta panels). (PDF $4856 \mathrm{~kb}$ )

Additional file 3: Movie S1. Basal protrusion dynamics in a control SOP cell. SOP cell expressing UAS-GMCA under the neur-GAL4 driver. Movie represents a maximum projection over $2.1 \mu \mathrm{m}$. Time in seconds. Scale bar, $10 \mu \mathrm{m}$. (AVl $4726 \mathrm{~kb}$ )

Additional file 4: Movie S2. Basal protrusion dynamics in a SOP cell with decreased myosin activity. SOP cell expressing UAS-GMCA and UASspaghetti squash $^{\mathrm{AA}}$ under the neur-GAL4 driver. Movie represents a maximum projection over $2.1 \mu \mathrm{m}$. Time in seconds. Scale bar, $10 \mu \mathrm{m}$. (AVI $8361 \mathrm{~kb})$

Additional file 5: Figure S3. Role of ligand endocytosis in Notch signaling. (A) Delta ligand endocytosis assay in SOP cells expressing LifeAct ${ }^{\text {Ruby }}$ (control) or zipper ${ }^{\text {DN }}$ under tubGAL80 ${ }^{\text {ts }}$; neur-GAL4, UASGMCA. Endocytosed Delta is specifically visualized through uptake of the anti-Delta (ECD) monoclonal antibody, red puncta (arrows). GFP is stained to visualize the SOP cell body. We find no significant difference in numbers of Delta positive puncta between the control or myosin II perturbed genotypes (graph). (B-C) RNAi against key regulator of ligand endocytosis pathway (liquid facets) lead to a pairing phenotype (indicated by yellow brackets). Pairs of neuralized expressing cells are seen with less frequency in control pupae. (B-C) Scale bars, $25 \mu \mathrm{m}$. (D-E) Quantifications of patterns for genotypes in (B-C). (D) Apical 'cell' diameter, measuring grouping/ pairing. ${ }^{* *} p<0.001$ by unpaired t-test. (E) Measurements of the distance between neuralized expressing cells. ${ }^{* * *} p<0.001$ by unpaired t-test. (n), number of distances measured, $N \geq 3$ nota measured for each genotype at $\sim 14 \mathrm{~h}$ AP. (F) Grouping is observed in cells co-expressing RNAi targeting zipper and liquid facets in SOP cells, compared to either RNAi expressed in SOP cells alone. We note that the grouping phenotype is slightly different in neur-GAL4, UAS-GMCA (D) and tubGAL80 $80^{\text {ts }}$; neurGAL4, UAS-GMCA (F) background, for unclear reasons. (PDF $5104 \mathrm{~kb}$ )

Additional file 6: Figure S4. Data supporting main Fig. 6. (A) additional panels of the same genotype and treatment as in Fig. 6B-B". Filamentous actin in red, phosphorylated myosin regulatory light chain in greyscale. Basal projection images are a maximum intensity projection over 2-4 $\mu \mathrm{m}$ to visualize protrusions. Single slice images are a single $z$-plane with in the projection images that show the pMRLC puncta. (B) Cartoon to clarify the genetics of the GRASP experiment in Fig. 6C-C". (PDF $3497 \mathrm{~kb}$ )

Additional file 7: Movie S3. Basal protrusion dynamics in notum explant. Nota expressing UAS-LifeAct-Ruby under the pnr-GAL4 driver to visualize filamentous actin in all epithelial cells. This movie is from a tissue explant cultured in Clone8 medium. Movie represents a single z-plane, time stamp: (minutes to seconds). Scale bar, 10 um. (AVI $1802 \mathrm{~kb}$ )

Additional file 8: Raw data file. Data analyzed for the main and supplemental figures. (XLSX $245 \mathrm{~kb}$ )

\section{Acknowledgements}

We thank Dan Kiehart (Duke University) for UAS-zipper ${ }^{\text {DN, GFP }}$ stocks, Chi-Hon Lee (NICHD) for GRASP transgenic stocks, and Marc Muskavitch for Delta antibody (guinea pig). Fly stocks obtained from the Bloomington Drosophila
Stock Center (NIH P40OD018537) were used in this study. Laser ablation experiments were performed with the help of members of the Kiehart Lab (Duke University). Microscopy was performed with the help of Vincent Schram (NICHD) and Carolyn Smith (NINDS). We thank Dr. Stephane Romero for his critical reading and comments. We are thankful to members of the Baum, Charras, and Giniger Labs for their technical advice and manuscript edits.

\section{Funding}

This work was supported by the National Institutes of Health (Z01 NS003013 to E.G. and R21DA039582 to N.P.); the Howard Hughes Medical Institute (N.P.); a Damon Runyon Cancer Research Foundation (to L.H.) the Biotechnology and Biological Research Council (BB/J008532/1 to B.B. and G.C.); a Cancer Research UK fellowship (to B.B.) and University College London (to B.B.). Laser ablation microscopy in the Kiehart lab is supported by $\mathrm{NIH}$ GM033830 to DPK.

\section{Availability of data and materials}

All data generated or analyzed during this study are included in this published article and its supplementary information files. The datasets, animals, and reagents used and/or analyzed during the current study are also available from the corresponding author on reasonable request.

\section{Authors' contributions}

$G L H, L H, E G$, and $B B$ wrote the manuscript. GLH and BB designed the experiments. GLH performed and analyzed the fly experiments. $L H$ performed and analyzed the cell culture experiments. Project funding was acquired by $G C, E G$, and $B B$. GH, EG, and $B B$ were responsible for the overall direction of the project. All authors read and approved the final manuscript.

\section{Ethics approval and consent to participate}

Not applicable.

\section{Consent for publication}

Not applicable.

\section{Competing interests}

The authors declare that they have no competing interests.

\section{Publisher's Note}

Springer Nature remains neutral with regard to jurisdictional claims in published maps and institutional affiliations.

\section{Author details}

${ }^{1}$ National Institute of Neurological Disorders and Stroke, NIH, Bethesda, MD 20892, USA. ${ }^{2}$ MRC-LMCB, University College London, London WC1E6BT, UK. ${ }^{3}$ Institute for the Physics of Living Systems, University College London, London WC1E6BT, UK. ${ }^{4}$ Department of Genetics, Harvard Medical School, Howard Hughes Medical Institute, Boston, MA 02115, USA. ${ }^{5}$ London Centre for Nanotechnology, University College London, London WC1E6BT, UK. ${ }^{6}$ Department of Cell and Developmental Biology, University College London, London WC1E6BT, UK. ${ }^{7}$ Present Address: Department of Biology, Clarkson University, Potsdam, NY 13699, USA.

Received: 30 October 2018 Accepted: 4 January 2019

Published online: 11 February 2019

\section{References}

1. Paluch E, Heisenberg C-P. Biology and physics of cell shape changes in development. Curr Biol. 2009;19(17):R790-9.

2. Köster DV, Mayor S. Cortical actin and the plasma membrane: inextricably intertwined. Curr Opin Cell Biol. 2016;38:81-9.

3. Levayer R, Lecuit T. Biomechanical regulation of contractility: spatial control and dynamics. Trends Cell Biol. 2012;22(2):61-81.

4. Chalut KJ, Paluch EK. The actin cortex: a bridge between cell shape and function. Dev Cell. 2016:38(6):571-3.

5. Forgacs G. Role of the cytoskeleton in signaling networks. J Cell Sci. 2004; 117(13):2769-75.

6. Iskratsch T, Wolfenson H, Sheetz MP. Appreciating force and shape - the rise of mechanotransduction in cell biology. Nat Rev Mol Cell Biol. 2014; 15(12):825-33. 
7. Gordon WR, Zimmerman B, He L, Miles LJ, Huang J, Tiyanont K, et al. Mechanical allostery: evidence for a force requirement in the proteolytic activation of notch. Dev Cell. 2015;33(6):729-36.

8. Luca VC, Kim BC, Ge C, Kakuda S, Wu D, Roein-Peikar M, et al. Notch-jagged complex structure implicates a catch bond in tuning ligand sensitivity. Science. 2017:355(6331):1320-4.

9. Meloty-Kapella L, Shergill B, Kuon J, Botvinick E, Weinmaster G. Notch ligand endocytosis generates mechanical pulling force dependent on dynamin, epsins, and actin. Dev Cell. 2012;22(6):1299-312.

10. Ploscariu N, Kuczera K, Malek KE, Wawrzyniuk M, Dey A, Szoszkiewicz R. Single molecule studies of force-induced S2 site exposure in the mammalian notch negative regulatory domain. J Phys Chem B. 2014; 118(18):4761-70

11. Shergill B, Meloty-Kapella L, Musse AA, Weinmaster G, Botvinick E. Optical tweezers studies on notch: single-molecule interaction strength is independent of ligand endocytosis. Dev Cell. 2012;22(6):1313-20.

12. Wang $X, \mathrm{Ha} \mathrm{T}$. Defining single molecular forces required to activate integrin and notch signaling. Science. 2013;340(6135):991-4.

13. Mooren OL, Galletta BJ, Cooper JA. Roles for actin assembly in endocytosis. Annu Rev Biochem. 2012;81(1):661-86.

14. Musse AA, Meloty-Kapella L, Weinmaster G. Notch ligand endocytosis: mechanistic basis of signaling activity. Semin Cell Dev Biol. 2012;23(4):429-36.

15. Ferguson JP, Huber SD, Willy NM, Aygün E, Goker S, Atabey T, et al. Mechanoregulation of clathrin-mediated endocytosis. J Cell Sci. 2017; 130(21):3631-6.

16. Fritzsche M, Li D, Colin-York H, Chang VT, Moeendarbary E, Felce JH, et al. Self-organizing actin patterns shape membrane architecture but not cell mechanics. Nat Commun. 2017:8:14347.

17. Köster DV, Husain K, Iljazi E, Bhat A, Bieling P, Mullins RD, et al. Actomyosin dynamics drive local membrane component organization in an in vitro active composite layer. Proc Natl Acad Sci. 2016;113(12):E1645-54.

18. Artavanis-Tsakonas S, Simpson P. Choosing a cell fate: a view from the Notch locus. Trends Genet. 1991;7(11):403-8.

19. Furman D, Bukharina T. How Drosophila melanogaster forms its mechanoreceptors. Curr Genomics. 2008;9(5):312-23.

20. Troost T, Schneider M, Klein T. A re-examination of the selection of the sensory organ precursor of the bristle sensilla of Drosophila melanogaster. PLoS Genet. 2015;11(1):e1004911 Desplan C, editor.

21. Curran S, Strandkvist C, Bathmann J, de Gennes M, Kabla A, Salbreux G, et al. Myosin II controls junction fluctuations to guide epithelial tissue ordering. Dev Cell. 2017;43(4):480-492.e6.

22. Franke JD, Montague RA, Kiehart DP. Nonmuscle myosin II generates forces that transmit tension and drive contraction in multiple tissues during dorsal closure. Curr Biol. 2005;15(24):2208-21.

23. Munjal A, Lecuit T. Actomyosin networks and tissue morphogenesis. Development. 2014;141(9):1789-93.

24. Hunter GL, Hadjivasiliou Z, Bonin H, He L, Perrimon N, Charras G, et al. Coordinated control of Notch/Delta signalling and cell cycle progression drives lateral inhibition-mediated tissue patterning. Development. 2016; 143(13):2305-10.

25. Karess RE, Chang $X$, Edwards KA, Aguilera I, Kiehartt DP. The regulatory light chain of nonmuscle myosin is encoded by spaghetti-squash, a gene required for cytokinesis in Drosophila. Cell. 1991;65:1177-89.

26. Kiehart DP, Lutz MS, Chan D, Ketchum AS, Laymon RA, Goldstein LSB. Identification of the gene for fly non-muscle myosin heavy chain: Drosophila myosin heavy chains are encoded by a gene family. EMBO J. 1989;8(3):913-22.

27. Vasquez CG, Tworoger M, Martin AC. Dynamic myosin phosphorylation regulates contractile pulses and tissue integrity during epithelial morphogenesis. J Cell Biol. 2014;206(3):435-50.

28. Verdier V, Chen, GC, Settleman, J. Rho-kinase regulates tissue morphogenesis via non-muscle myosin and LIM-kinase during Drosophila development. BMC Dev Biol. 2006;6:38.

29. Amano M, Ito M, Kimura K, Fukata Y, Chihara K, Nakano T, et al. Phosphorylation and activation of myosin by rho-associated kinase (rhokinase). J Biol Chem. 1996;271(34):20246-9.

30. Kasza KE, Farrell DL, Zallen JA. Spatiotemporal control of epithelial remodeling by regulated myosin phosphorylation. Proc Natl Acad Sci. 2014; 111(32):11732-7.

31. Ishizaki T, Uehata M, Tamechika I, Keel J, Nonomura K, Maekawa M, et al. Pharmacological properties of $\mathrm{Y}-27632$, a specific inhibitor of rho-associated kinases. Mol Pharmacol. 2000;57:976-83.
32. Hartenstein V, Posakony JW. A dual function of the Notch gene in Drosophila sensillum development. Dev Biol. 1990;142(1):13-30.

33. Cohen M, Georgiou M, Stevenson NL, Miodownik M, Baum B. Dynamic filopodia transmit Intermittent Delta-notch signaling to drive pattern refinement during lateral inhibition. Dev Cell. 2010;19(1):78-89.

34. Hadjivasiliou Z, Hunter GL, Baum B. A new mechanism for spatial pattern formation via lateral and protrusion-mediated lateral signalling. J R Soc Interface. 2016;13(124):20160484.

35. Kiehart DP, Galbraith CG, Edwards KA, Rickoll WL, Montague RA. Multiple forces contribute to cell sheet morphogenesis for dorsal closure in Drosophila. J Cell Biol. 2000;149(2):471-90.

36. Leijnse N, Oddershede LB, Bendix PM. Helical buckling of actin inside filopodia generates traction. Proc Natl Acad Sci. 2015;112(1):136-41.

37. Elliott H, Fischer RS, Myers KA, Desai RA, Gao L, Chen CS, et al. Myosin II controls cellular branching morphogenesis and migration in three dimensions by minimizing cell-surface curvature. Nat Cell Biol. 2015;17(2):137-47.

38. Boulant $\mathrm{S}$, Kural $\mathrm{C}$, Zeeh J-C, Ubelmann F, Kirchhausen T. Actin dynamics counteract membrane tension during clathrin-mediated endocytosis. Nat Cell Biol. 2011;13(9):1124-31.

39. Liu J, Sun Y, Oster GF, Drubin DG. Mechanochemical crosstalk during endocytic vesicle formation. Curr Opin Cell Biol. 2010;22(1):36-43.

40. Langridge PD, Struhl G. Epsin-dependent ligand endocytosis activates Notch by force. Cell. 2017:171(6):1383-1396.e12.

41. Couturier L, Schweisguth F. Antibody uptake assay and in vivo imaging to study intracellular trafficking of Notch and Delta in Drosophila. In: Bellen HJ, Yamamoto S, editors. Notch signaling: methods and protocols. New York, NY: Springer New York; 2014. p. 79-86. Available from: https://doi.org/10. 1007/978-1-4939-1139-4_6.

42. Wang W, Struhl G. Drosophila Epsin mediates a select endocytic pathway that DSL ligands must enter to activate Notch. Development. 2004;131(21):5367-80.

43. Macia E, Ehrlich M, Massol R, Boucrot E, Brunner C, Kirchhausen T. Dynasore, a cell-permeable inhibitor of dynamin. Dev Cell. 2006;10(6):839-50.

44. Rauzi M, Lenne P-F, Lecuit T. Planar polarized actomyosin contractile flows control epithelial junction remodelling. Nature. 2010:468(7327): $1110-4$

45. Lowe N, Rees JS, Roote J, Ryder E, Armean IM, Johnson G, et al. Analysis of the expression patterns, subcellular localisations and interaction partners of Drosophila proteins using a pigP protein trap library. Development. 2014; 141(20):3994-4005.

46. Craig EM, Van Goor D, Forscher P, Mogilner A. Membrane tension, myosin force, and actin turnover maintain actin treadmill in the nerve growth cone. Biophys J. 2012;102(7):1503-13.

47. Medeiros NA, Burnette DT, Forscher P. Myosin II functions in actin-bundle turnover in neuronal growth cones. Nat Cell Biol. 2006;8(3):216-26.

48. Feinberg EH, VanHoven MK, Bendesky A, Wang G, Fetter RD, Shen K, et al. GFP reconstitution across synaptic partners (GRASP) defines cell contacts and synapses in living nervous systems. Neuron. 2008;57(3): 353-63.

49. Tseng Q, Duchemin-Pelletier E, Deshiere A, Balland M, Guillou H, Filhol O, et al. Spatial organization of the extracellular matrix regulates cell-cell junction positioning. Proc Natl Acad Sci. 2012;109(5):1506-11.

50. Bray SJ. Notch signalling in context. Nat Rev Mol Cell Biol. 2016;17(11): 722-35.

51. de Joussineau C, Soulé J, Martin M, Anguille C, Montcourrier P, Alexandre D. Delta-promoted filopodia mediate long-range lateral inhibition in Drosophila. Nature. 2003;426(6966):555-9.

52. Renaud O, Simpson P. Scabrous modifies epithelial cell adhesion and extends the range of lateral Signalling during development of the spaced bristle pattern in Drosophila. Dev Biol. 2001;240(2):361-76.

53. Khait I, Orsher Y, Golan O, Binshtok U, Gordon-Bar N, Amir-Zilberstein L, et al. Quantitative analysis of Delta-like 1 membrane dynamics elucidates the role of contact geometry on notch signaling. Cell Rep. 2016;14(2):225-33

54. Bornschlogl T, Romero S, Vestergaard CL, Joanny J-F, Van Nhieu GT, Bassereau P. Filopodial retraction force is generated by cortical actin dynamics and controlled by reversible tethering at the tip. Proc Natl Acad Sci. 2013;110(47):18928-33.

55. Xie X, Cho B, Fischer JA. Drosophila Epsin's role in Notch ligand cells requires three Epsin protein functions: the lipid binding function of the ENTH domain, a single ubiquitin interaction motif, and a subset of the C-terminal protein binding modules. Dev Biol. 2012;363(2):399-412. 
56. Heusermann W, Hean J, Trojer D, Steib E, von Bueren S, Graff-Meyer A, et al. Exosomes surf on filopodia to enter cells at endocytic hot spots, traffic within endosomes, and are targeted to the ER. J Cell Biol. 2016; 213(2):173-84.

57. Cohen M, Baum B, Miodownik M. The importance of structured noise in the generation of self-organizing tissue patterns through contact-mediated cellcell signalling. J R Soc Interface. 2011;8(59):787-98.

58. Eldar A, Elowitz MB. Functional roles for noise in genetic circuits. Nature. 2010;467(7312):167-73

59. Hsu C, Jaquet V, Maleki F, Becskei A. Contribution of Bistability and noise to cell fate transitions determined by feedback opening. J Mol Biol. 2016; 428(20):4115-28

60. Losick R, Desplan C. Stochasticity and cell fate. Science. 2008;320(5872):65-8.

61. Palani S, Sarkar CA. Transient noise amplification and gene expression synchronization in a Bistable mammalian cell-fate switch. Cell Rep. 2012;1(3): 215-24.

62. Heitzler P, Bourouis M, Ruel L, Carteret C, Simpson P. Genes of the Enhancer of split and achaete-scute complexes are required for a regulatory loop between Notch and Delta during lateral signalling in Drosophila. Development. 1996;122:161-71.

63. Parks AL, Shalaby NA, Muskavitch MAT. Notch and suppressor of Hairless regulate levels but not patterns of Delta expression in Drosophila. Genesis. 2008;46(5):265-75.

64. Trylinski M, Mazouni K, Schweisguth F. Intra-lineage fate decisions involve activation of Notch receptors basal to the midbody in Drosophila sensory organ precursor cells. Curr Biol. 2017;27(15):22392247.e3.

65. Corson F, Couturier L, Rouault H, Mazouni K, Schweisguth F. Self-organized Notch dynamics generate stereotyped sensory organ patterns in Drosophila. Science. 2017;356(6337):eaai7407.

66. Doe C, Goodman C. Early events in insect neurogenesis. Dev Biol. 1985;111: 206-19.

67. Kornberg TB. Distributing signaling proteins in space and time: the province of cytonemes. Curr Opin Genet Dev. 2017;45:22-7.

68. Loubéry S, González-Gaitán M. Monitoring Notch/Delta endosomal trafficking and signaling in Drosophila. In: Methods in Enzymology: Elsevier. 2014;534:301-21.

69. Hutson MS. Forces for morphogenesis investigated with laser microsurgery and quantitative modeling. Science. 2003:300(5616):145-9.

70. Zhou R, Mohr S, Hannon GJ, Perrimon N. Inducing RNAi in Drosophila cells by transfection with dsRNA. Cold Spring Harb Protoc. 2013;2013(5):pdb. prot074351.

71. de Chaumont F, Dallongeville S, Chenouard N, Hervé N, Pop S, Provoost T, et al. Icy: an open bioimage informatics platform for extended reproducible research. Nat Methods. 2012;9(7):690-6.

Ready to submit your research? Choose BMC and benefit from:

- fast, convenient online submission

- thorough peer review by experienced researchers in your field

- rapid publication on acceptance

- support for research data, including large and complex data types

- gold Open Access which fosters wider collaboration and increased citations

- maximum visibility for your research: over $100 \mathrm{M}$ website views per year

At $\mathrm{BMC}$, research is always in progress.

Learn more biomedcentral.com/submissions 